\title{
THE EFFECTS OF LACTOBACILLUS PLANTARUM IS-10506 ON ACCELERATING THE REGENERATION OF THE INTESTINAL MUCOSA STRUCTURE EXAMINED BY THE SCANNING ELECTRON MICROSCOPE
}

\author{
Alpha Fardah Athiyyah ${ }^{*}$, Andy Darma ${ }^{1}$, Reza Gunadi Ranuh ${ }^{1}$, W. Riawan ${ }^{2}$, I.K. Sudiana ${ }^{3}$, I.S. \\ Surono $^{4}$, Subijanto Marto Sudarmo ${ }^{1}$ \\ ${ }^{I}$ Department of Child Health Dr. Soetomo Hospital, Faculty of Medicine, Universitas Airlangga, Surabaya, Indonesia \\ ${ }^{2}$ Laboratory of Biochemistry and Biomolecular Universitas Brawijaya, Malang, Indonesia \\ ${ }^{3}$ Electron Microscope Unit, Faculty of Medicine Universitas Airlangga, Surabaya, Indonesia \\ ${ }^{4}$ Food Technology Department, Faculty of Engineering, Universitas Bina Nusantara, Jakarta, Indonesia \\ *alpha-f-a@fk.unair.ac.id \\ https://doi.org/10.34302/crpjfst/2019.11.5.2 \\ Article history: \\ Received: \\ 9 March 2019 \\ Accepted: \\ 20 September 2019 \\ Keywords: \\ Probiotics; \\ Regeneration; \\ Intestinal Mucosa; \\ Scanning Electron Microscope \\ (SEM);

\begin{abstract}
Lactobacillus plantarum IS-10506 (LIS-10506) is a native Indonesian probiotic derived from fermented milk originating from Sumatera. Intestinal mucosa damage results from gastrointestinal tract infections. Using Scanning Electron Microscopy (SEM), the intestinal mucosa structure, following mucosal damage, was evaluated. The objective of this study to evaluate effect of Lactobacillus plantarum IS-10506 on accelerating the regeneration of the intestinal mucosa structure, using SEM. This study conducted on sixty-four Sprague-Dawley rats were divided into 4 groups: control group $\left(\mathrm{K}_{1}\right)$; the group that received Lipopolysaccharide (LPS) Escherichia coli $\mathrm{O} 55: \mathrm{B} 5\left(\mathrm{~K}_{2}\right)$; the curative group, which received LPS Escherichia coli $\mathrm{O55}$ :B5 then probiotics $\left(\mathrm{K}_{3}\right)$; the preventive group, which received probiotics six days before LPS Escherichia coli O55:B5 and continued probiotics $\left(\mathrm{K}_{4}\right)$. The probiotics used were LIS-10506. Necroscopy was performed on days 3, 4, 6 and 7, and the ileum was analysed. SEM was conducted to evaluate the structure of the intestinal mucosa. SEM showed that the $\mathrm{K}_{4}$ group experienced the fastest mucosal regeneration on the fourth day. On the seventh day, examination of the ileum using SEM showed improvement in the intestinal villi of all groups. The conclusion, SEM showed that all groups underwent regeneration following mucosal damage. Probiotics accelerated the regeneration of the intestinal mucosa, and the best results were observed in the preventive group.
\end{abstract}

\section{Introduction}

Probiotics have been shown to shorten the duration of diarrhoea in children with infectious diarrhoea (Allen et al., 2011). Recovery from diarrhoea is closely related to damaged intestinal epithelial repair. Lactobacillus plantarum IS strains 10506 and 20506 have demonstrated a regenerative effect on the intestinal brush border protein, which was represented by the expression of Galectin-4, Myosin-1a, Occludin and ZO-1 (Ranuh, 2008). Research conducted by Ciorba found that the administration of probiotics can affect mesenchymal stem cells by invoking their migration towards the crypts, and consequently increasing crypt survival (Ciorba et al., 2012).

Lactobacillus plantarum IS-10506 is a native Indonesian probiotic derived from curd, fermented milk from Sumatera (Collado et al., 2007; Collado et al., 2016). Exposure of the intact epithelium to probiotics activates Hsp27 and IL-10. Hsp27 and IL-10 affect intestinal 
stem cell niche, as IL-10 will activate the JAK/STAT pathway, and both Hsp27 and IL-10 will activate stromal cells, paneth cells and intestinal stem cells. Signalling pathways stimulate proliferation of activate stem cells, followed by differentiation and maturation. Other studies have shown that L. plantarum IS10506 increases the expression of Lgr-5 and Bmi1. L. plantarum IS-10506 also induces activation of intestinal stem cell pool by increasing ERK and $\beta$-catenin expression, reducing intestinal mucosal injury caused by inflammation. These findings suggest that $L$. plantarum IS-10506 is a potentially effective therapy, especially when used as prophylaxis for gastrointestinal diseases (Athiyyah et al., 2018).

Therefore, a study is needed to show the regeneration of intestinal mucosa by the probiotic Lactobacillus plantarum IS-10506 using Scanning Electron Microscopy (SEM) to evaluate the surface structure of the ileum.

\section{Materials and methods}

\subsection{Lipopolysaccharides (LPS)}

LPS used in this study came from Escherichia coli bacteria serotype 055:B5. LPS was diluted with $\mathrm{NaCl} 0.9 \%$, at a ratio of $10: 1$, and administered at a dose of $250 \mu \mathrm{g} / \mathrm{kg}$ bw through a gastric tube on day 1 of the study to groups $\mathrm{K}_{2}, \mathrm{~K}_{3}$ and $\mathrm{K}_{4}$.

\subsection{Probiotic}

Microencapsulated Lactobacillus plantarum IS-10506 (GeneBank accession n ${ }^{\circ}$ DQ860148) was dissolved in $1.5 \mathrm{ml}$ of sterile water and administered daily, through a gastric tube, at a of dose $2.86 \times 10^{10} \mathrm{CFU} /$ day. The probiotic was given for 6 days to the $K_{3}$ group and 13 days to the $\mathrm{K}_{4}$ group.

\subsection{Animals}

This research was approved by the Ethics Committee (Animal Care and Use Committee) of Veterinary Medicine School, Universitas
Airlangga (Surabaya, Indonesia). Subjects of this study were male Sprague-Dawley rats (Rattus norvegicus) obtained from the animal management unit of the veterinary faculty of Bogor Agricultural Institute (12 weeks old; 100 120 grams; $n=64)$, randomised into 4 groups: $\mathrm{K}_{1}$ (control group); $\mathrm{K}_{2}$ (Lipopolysaccharide (LPS) Escherichia coli O55:B5 group); $\mathrm{K}_{3}$ (LPS Escherichia coli O55:B5 + Lactobacillus plantarum IS-10506 group); $\mathrm{K}_{4}$ (Lactobacillus plantarum IS-10506 + LPS Escherichia coli O55:B5 + Lactobacillus plantarum IS-10506 group). $\mathrm{K}_{1}$ was given the placebo via tube for 14 days, which consisted of sterile water. LPS Escherichia coli O55:B5 was administered at $250 \mu \mathrm{g} / \mathrm{kg}$ bw/day, starting on day 1 , of the study for all groups except group $\mathrm{K}_{1}$. Lactobacillus plantarum IS-10506 were administered via tube every day at a dose of $2.86 \times 10^{10} \mathrm{CFU}$; group $\mathrm{K}_{3}$ received this probiotic for 6 days and group $\mathrm{K}_{4}$ received it for 13 days. This methods is part of a study on intestinal mucose (Athiyyah et al., 2018). After observation and treatment, the subjects were sacrificed on days 3, 4, 6 and 7 by guillotine and the ileum was analysed. The anatomical structure of the ileum was determined by electron microscopy.

\subsection{SEM}

For the organic SEM process, fresh samples should be observed. The ileum was fixed in a $2 \%$ glutaraldehyde solution for $2-3$ hours at $4{ }^{\circ} \mathrm{C}$. The samples were washed with $\mathrm{pH} 7.4$ phosphate buffer solution (PBS) (SIGMA, USA) 3 times, 5 minutes each time, at $4{ }^{\circ} \mathrm{C}$. The PBS was replaced with a $1 \%$ post fixation osmic acid solution for $1-2$ hours at $4{ }^{\circ} \mathrm{C}$. The samples were then washed with $\mathrm{pH} 7.4$ PBS 3 times, 5 minutes each time, at $4{ }^{\circ} \mathrm{C}$. The samples were gradually dehydrated with alcohol: $30 \%, 50 \%$, $70 \%, 80 \%, 90 \%$ and absolute, 2 times each, for 15-20 minutes. Dehydration using 30\%-70\% alcohol was performed at $4{ }^{\circ} \mathrm{C}$, and dehydration using 80\%-absolute alcohol was performed at room temperature. The alcohol was then replaced with absolute amyl acetate (MERCK, D-6100 Darmstadt, F.R. Germany), as a preservative to wait for drying time. The 
samples were dried using the Critical Point Drying (CPD) procedure (Samdri $\left.{ }^{\circledR}-780\right)$, with a pressure of $1000 \mathrm{psi}$, at $45^{\circ} \mathrm{C}$. Each sample was attached to the stub (holder) using Araldite $\left(\right.$ Araldite ${ }^{\circledR}$ ) and coated with pure gold using a vacuum evaporator (JEOL, JEE-4X Thermal Evaporator Operation OPER-001). Finally, the samples were observed and photographed using SEM (JEOL, JSM-T100 Scanning Microscope).

\section{Results and discussions}

The ileum surface structure was visualised by SEM, and the results of the structure on the third day can be seen in Figure 1 for each group. At 350x magnification, an intact surface epithelial structure was observed in the $\mathrm{K}_{1}$ group. For the $\mathrm{K}_{2}$ group, the villi structure was damaged and the epithelium had an irregular arrangement. The damage observed in the $\mathrm{K}_{3}$ group was more severe compared to the $\mathrm{K}_{2}$ group. Damaged villi and epithelium were also observed in the $\mathrm{K}_{4}$ group, but not as severe as that observed in the $\mathrm{K}_{2}$ and $\mathrm{K}_{3}$ groups.

On the fourth day (Figure 2), a slight improvement in the structure of the epithelial villi was observed in the $\mathrm{K}_{2}$ group, but the structure was still irregular. The improvement observed in the $\mathrm{K}_{3}$ group was better than that observed in the $K_{2}$ group, and the greatest improvement was observed in the $\mathrm{K}_{4}$ group.

On the sixth day (Figure 3), the ileum structure of $\mathrm{K}_{3}$ and $\mathrm{K}_{4}$ appeared like normal intestinal villi, with a good villous structure and well-arranged epithelium; although, the $\mathrm{K}_{3}$ group had no improvement in the overall structure of the surface.

On the seventh day (Figure 4), an improvement in the intestinal villi was observed in all groups, as determined by SEM examination of the ileum.

SEM aims to evaluate the mucous structure of the ileum. Mucosal damage was found in the groups that received LPS Escherichia coli, $\mathrm{K}_{2}$, $\mathrm{K}_{3}$ and $\mathrm{K}_{4}$ groups. This result is in line with research conducted by Nikaido, which demonstrated that the administration of LPS parenterally can induce clinical manifestation in some species. In the gastrointestinal tract, bacterial endotoxins induce damage to the intestinal mucosa (Nikaido, 1996).

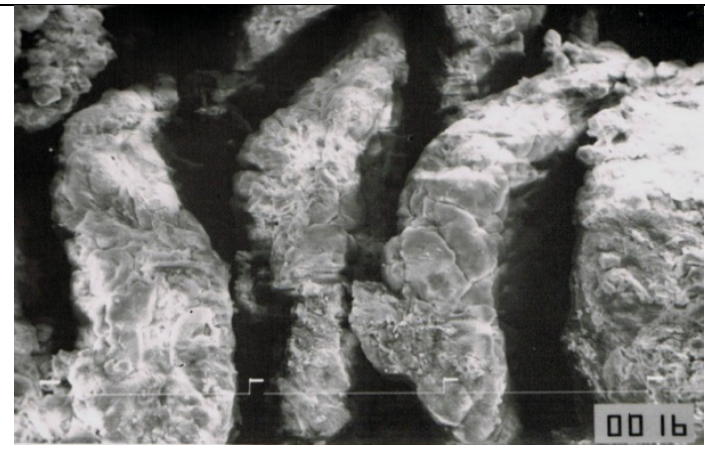

A. $\mathrm{K}_{1}$ group, day 3

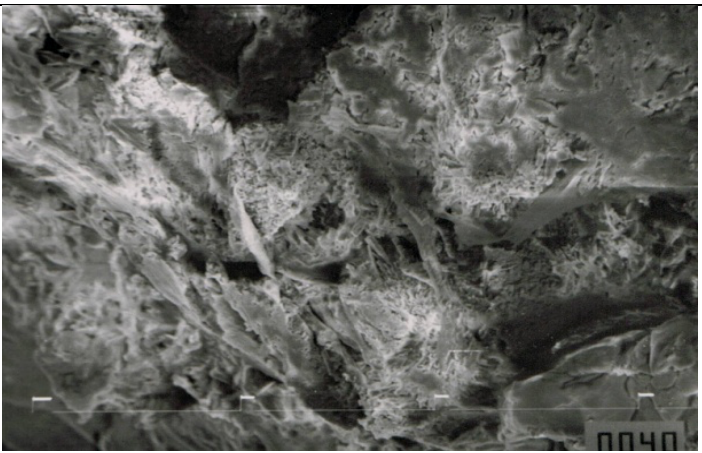

B. $\mathrm{K}_{2}$ group, day 3 


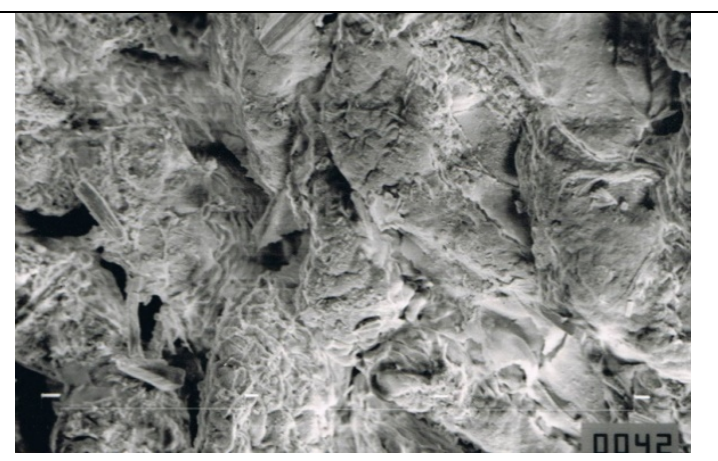

C. $\mathrm{K}_{3}$ group, day 3

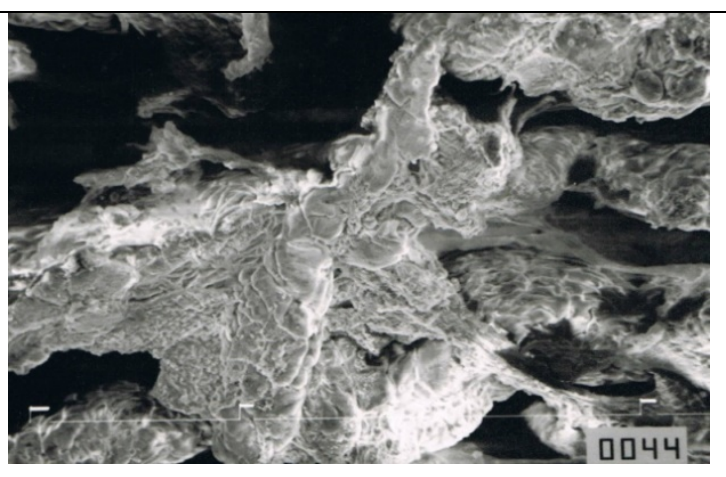

D. $\mathrm{K}_{4}$ group, day 3

Figure 1. Images of the ileum of Sprague-Dawley rats on the third day in the $\mathrm{K}_{1}, \mathrm{~K}_{2}, \mathrm{~K}_{3}$ and $\mathrm{K}_{4}$ groups obtained using SEM, with 350x lens magnification. $\mathrm{K}_{1}$ (control group); $\mathrm{K}_{2}$ (Lipopolysaccharide (LPS) Escherichia coli O55:B5 group); $\mathrm{K}_{3}$ (LPS Escherichia coli O55:B5 + Lactobacillus plantarum IS-10506 group); $\mathrm{K}_{4}$ (Lactobacillus plantarum IS-10506 + LPS Escherichia coli O55:B5 + Lactobacillus plantarum IS-10506 group).

SEM was carried out two days after the administration of LPS, which was considered the third day of this study. The probiotic, Lactobacillus plantarum IS-10506, was given on the second day. On the third day, damage was observed in the ileum of the $\mathrm{K}_{4}$ group, but this damage was not as severe as the damage observed in the $\mathrm{K}_{2}$ and $\mathrm{K}_{3}$ groups. The most severe damage was detected in the $\mathrm{K}_{2}$ group (Figure 1). Based on research conducted by Khonyoung, heat-killed Lactobacillus plantarum L-137 can increase protuberant cells in all intestinal segments, especially at doses of 2 and $4 \mathrm{mg} / \mathrm{kg}$ compared to the control and a dose of $1 \mathrm{mg} / \mathrm{kg}$. Thus, Lactobacillus plantarum L-137 can preserve intestinal function by preventing infection and disease in the intestinal mucosa. (Khonyoung and Yamauchi, 2012). The fastest intestinal repair was seen in the $\mathrm{K}_{4}$ group, followed by the $\mathrm{K}_{3}$ group and the $\mathrm{K}_{2}$ group, respectively, on the fourth day (Figure 2). On the seventh day, improvement in the structure of the intestinal mucosa was observed in all study groups. These results suggest that the administration of probiotics can accelerate the repair of the intestinal mucosa (Figure 4). The results of this study are in line with research conducted by Dock in 2004, which found there was mucous damage in the ileum of Wistar rats given protein-free food. Ileal mucosal damage was seen in the villi length, depth and thickness of the intestinal wall crypt. Probiotic administration (Streptococcus thermophilus and Lactobacillus helveticus) accelerated the repair of the intestinal mucosal damage ('Probiotics enhance the recovery of gut atrophy in experimental', 2004). Other studies also reported the same results, namely Lactobacillus casei MTCC 1423 accelerated repair in malnourished Balb/c mice infected with Giardia lamblia. The Lactobacillus casei MTCC 1423mediated repair was characterised by reduced Giardia trophozoites and improved histological morphology observed with haematoxylin eosin staining (Shukla and Sidhu, 2011). 

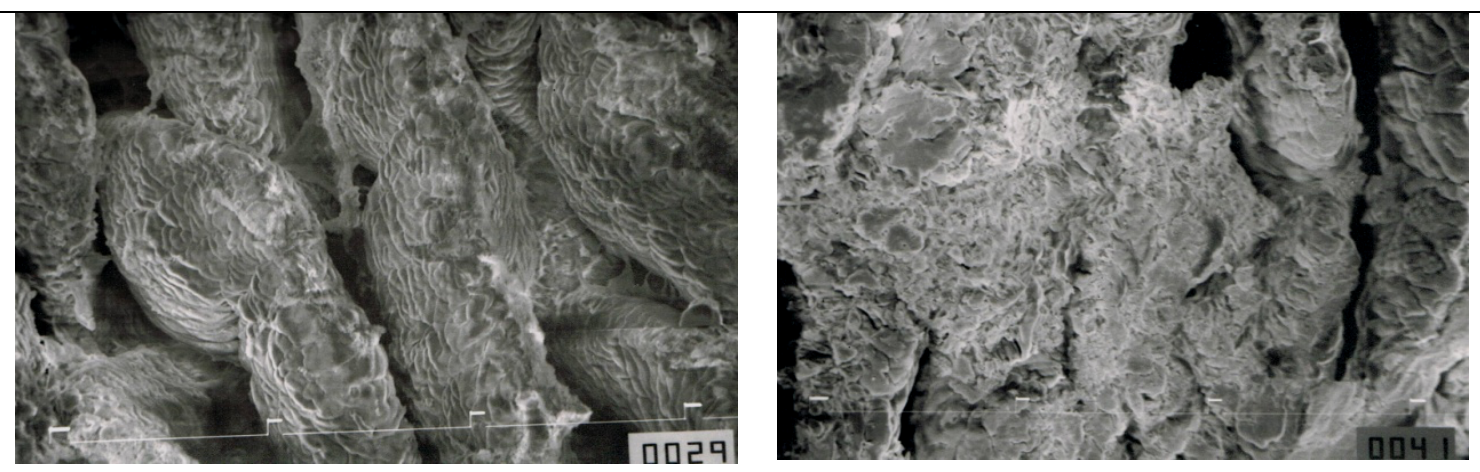

A. $\mathrm{K}_{1}$ group, day 4

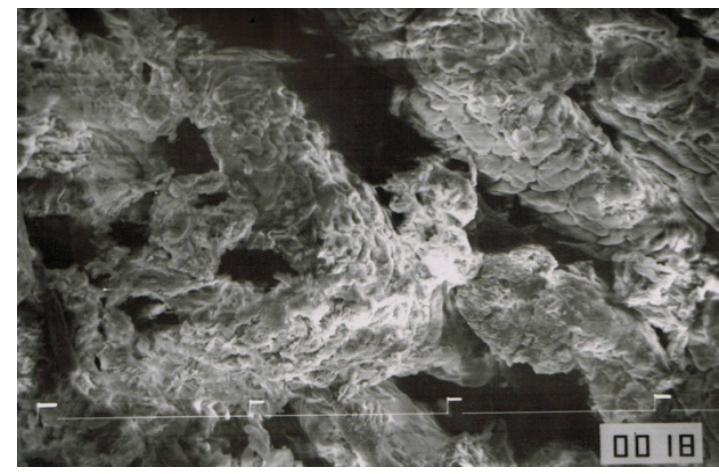

C. $\mathrm{K}_{3}$ group, day 4
B. $\mathrm{K}_{2}$ group, day 4

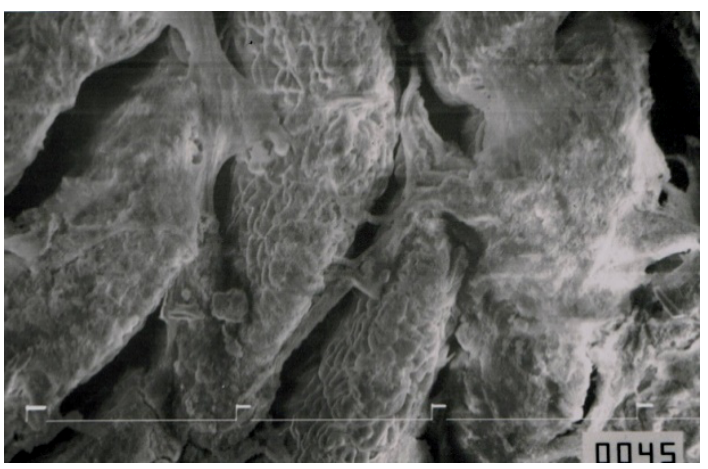

D. $\mathrm{K}_{4}$ group, day 4

Figure 2. Images of the ileum of Sprague-Dawley rats on the fourth day in the $\mathrm{K}_{1}, \mathrm{~K}_{2}, \mathrm{~K}_{3}$ and $\mathrm{K}_{4}$ groups obtained using SEM, with 350x lens magnification.

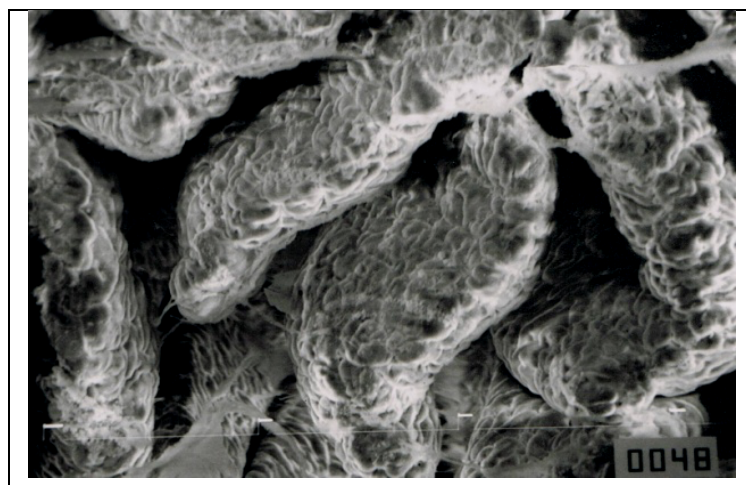

A. $\mathrm{K}_{1}$ group, day 6

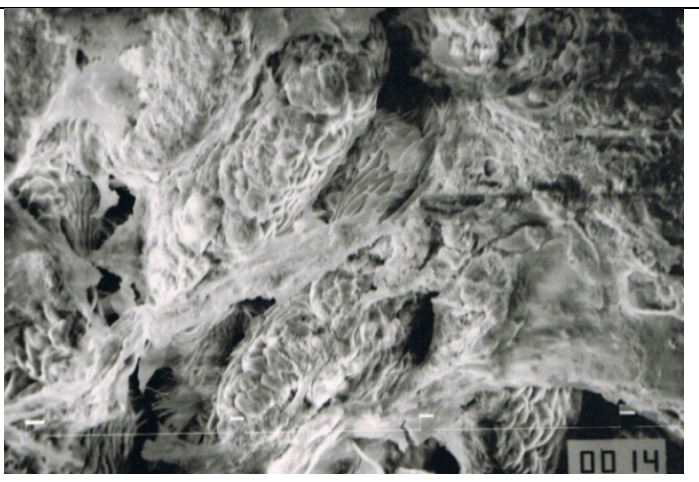

B. $\mathrm{K}_{2}$ group, day 6 


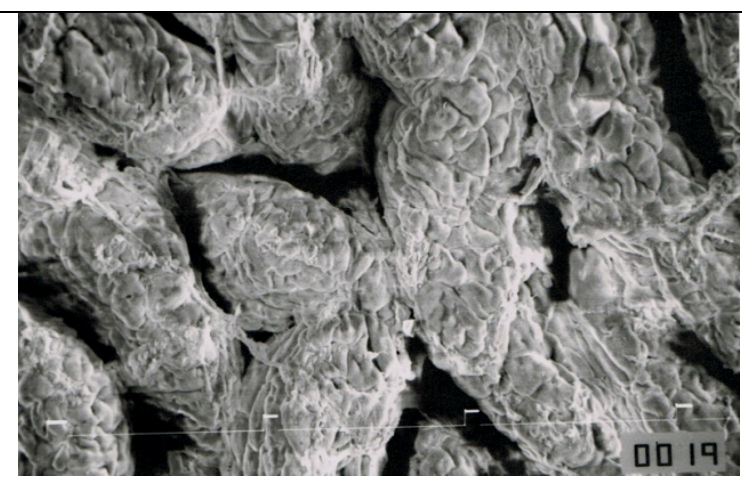

C. $\mathrm{K}_{3}$ group, day 6

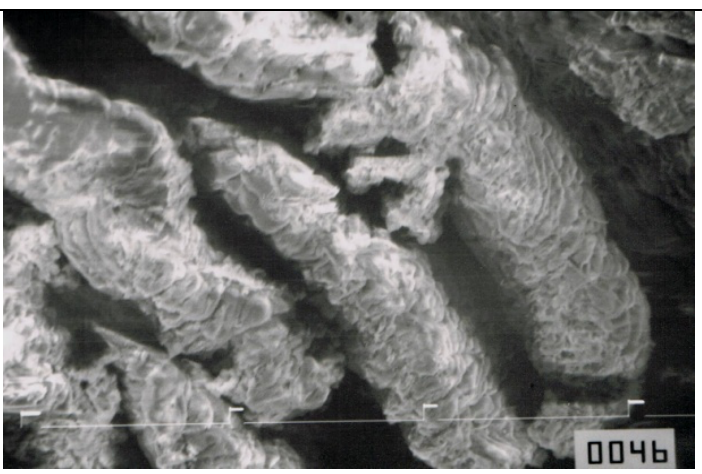

D. $K_{4}$ group, day 6

Figure 3. Images of the ileum of Sprague-Dawley rats on the sixth day in the $K_{1}, K_{2}, K_{3}$ and $K_{4}$ groups obtained using SEM, with 350x lens magnification.

Probiotics (Bacillus subtilis Bs964, Candida utilis BKM-Y74 and Lactobacillus acidophilus LH1F) can enhance the number lymph and lymphatic cells of the intestinal epithelium (IEL) in chicken caecal tonsils, based on research conducted by Yurong, which found an increase in the density and length of microvilli on the surface of the tonsil caecal villi (Yurong et al.,
2005). Another study stated that not all Lactobacillus strains adhere to enterocytes. Lactobacillus has been shown to inhibit in vitro growth and adhesion of various Salmonella strains, as well as the production of antimicrobial substances (Kankaanpää et al., 2004).

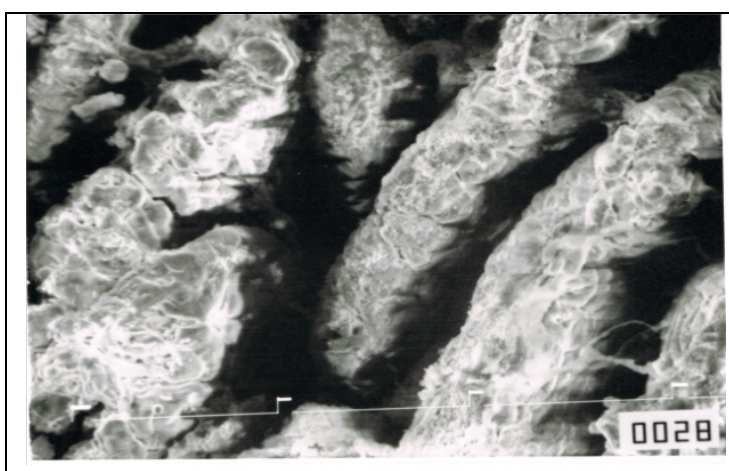

A. $\mathrm{K}_{1}$ group, day 7

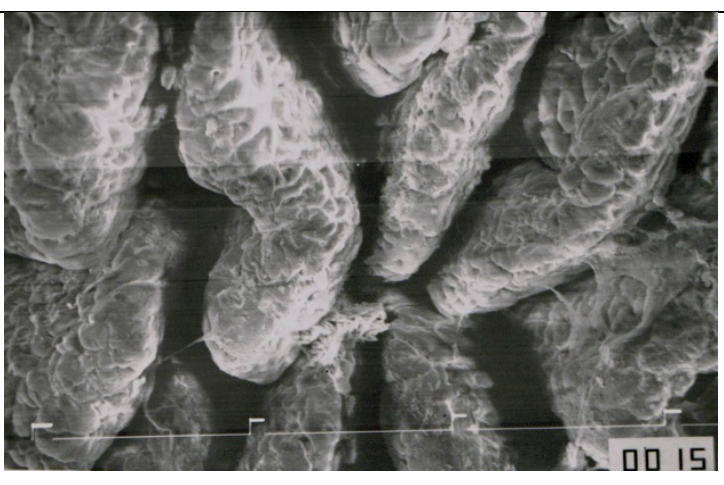

B. $\mathrm{K}_{2}$ group, day 7 


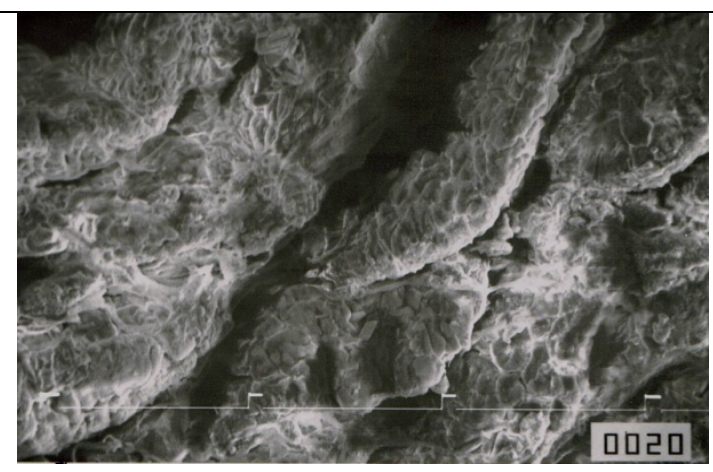

C. $\mathrm{K}_{3}$ group, day 7

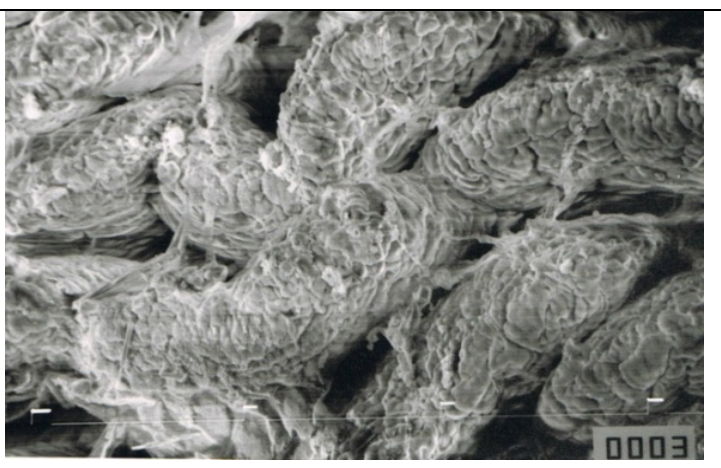

D. $\mathrm{K}_{4}$ group, day 7

Figure 4. Images of the ileum of Sprague-Dawley rats on the seventh day in the $\mathrm{K}_{1}, \mathrm{~K}_{2}, \mathrm{~K}_{3}$ and $\mathrm{K}_{4}$ groups obtained using SEM, with 350x lens magnification.

\section{Conclusions}

SEM showed that all groups experienced regeneration following mucosal damage. On the third day, damage was observed in the $\mathrm{K}_{4}$ group, but the damage was not as severe as that in the $\mathrm{K}_{2}$ and $\mathrm{K}_{3}$ groups. The regenerative process was most accelerated in the preventive group $\left(\mathrm{K}_{4}\right)$, which showed improvement on day 4 of the study.

\section{References}

Allen, S. J. et al. (2011) 'Cochrane Review: Probiotics for treating acute infectious diarrhoea', Evidence-Based Child Health: A Cochrane Review Journal, 6(6), pp. 1894 2021. doi: 10.1002/ebch.873.

Athiyyah, A. F. et al. (2018) 'Lactobacillus plantarum IS-10506 activates intestinal stem cells in a rodent model', Beneficial Microbes. doi: 10.3920/BM2017.0118.

Ciorba, M. A. et al. (2012) 'Lactobacillus probiotic protects intestinal epithelium from radiation injury in a TLR-2/cyclooxygenase-2-dependent manner.', Gut, 61(6), pp. 829-38. doi: 10.1136/gutjnl2011-300367.

Collado, M. C. et al. (2007) 'Indigenous dadih lactic acid bacteria: Cell-surface properties and interactions with pathogens', Journal of Food Science. doi: 10.1111/j.17503841.2007.00294.x.
Collado, M. C. et al. (2016) 'Potential Probiotic Characteristics of Lactobacillus and Enterococcus Strains Isolated from Traditional Dadih Fermented Milk against Pathogen Intestinal Colonization', Journal of Food Protection, 70(3), pp. 700-705. doi: 10.4315/0362-028x-70.3.700.

Kankaanpää, P. et al. (2004) 'Effects of Polyunsaturated Fatty Acids in Growth Medium on Lipid Composition and on Physicochemical Surface Properties of Lactobacilli', Applied and Environmental Microbiology, 70(1), pp. 129-136. doi: 10.1128/AEM.70.1.129-136.2004.

Khonyoung, D. and Yamauchi, K. E. (2012) 'Effects of heat-killed Lactobacillus plantarum L-137 on morphology of intestinal villi and epithelial cells in broiler chickens', Journal of Applied Animal Research, 40(2), pp. 140-147. doi: 10.1080/09712119.2011.640208.

Nikaido, H. (1996) 'Outer membrane. In: Neidhardt F C, Curtiss III R, Ingraham J L, Lin $\mathrm{E} \mathrm{C} \mathrm{C,} \mathrm{Low} \mathrm{K} \mathrm{B} \mathrm{Jr,} \mathrm{Magasanik} \mathrm{B,}$ Reznikoff W S, Riley M, Schaechter M, Umbarger H E, editors. Escherichia coli and Salmonella: cellular and molecular biology. 2nd ed. Washington, D.C: Amer', Microbiology and Molecular Biology Reviews, 67(4), pp. 29-47. doi: 10.1128/MMBR.67.4.593.

Ranuh, R. (2008) Ekspresi Protein Galectin-4, myosin-1a, Occludin dan ZO-1 sebagai efek 
pemberian probiotik lactobacillus plantarum IS pada perbaikan kerusakan Brush Border Usus Akibat Lipolysaccharide E. Coli [disertasi]. Surabaya: Universitas Airlangga.

'Probiotics enhance the recovery of gut atrophy in experimental' (2004), 28(2), pp. 143-150.

Shukla, G. and Sidhu, R. K. (2011) 'Lactobacillus casei as a probiotic in malnourished Giardia lamblia -infected mice: a biochemical and histopathological study ', Canadian Journal of Microbiology, 57(2), pp. 127-135. doi: 10.1139/w10-110.

Yurong, Y. et al. (2005) 'Effect of probiotics on intestinal mucosal immunity and ultrastructure of cecal tonsils of chickens', Archives of Animal Nutrition, 59(4), pp. 237-246.

doi:

10.1080/17450390500216928. Weizman, Z., Asli, G. and Alsheikh, A. (2005) 'Effect of a probiotic infant formula on infections in child care centers: comparison of two probiotic agents', Pediatrics, 115, pp. 5-9.

\section{Acknowledgment}

The authors thank all the teams who worked on this study. 